\title{
LAGARTO PANCHO \\ Tercer Puesto \\ en el Concurso literario UMCH 2016
}

Mike A. Herrán Sifuentes

Estudiante de Psicología de la UMCH

El cielo se llenó de nubes y una sombra tenebrosa cubrió la montaña verde del Brasil. Pasaron las horas y la lluvia se hizo más intensa. La gente se resguardaba en sus cabañas hechas de palma. De repente, en la orilla del río, por encima del barro, comenzó a deslizarse, un enorme huevo color marfil, el cual fue abrazado por unas piedras en forma de corazón.

Una embarcación llamada Reina María I, se preparaba para partir del puerto de Magazao llevando telas, con destino al puerto de lquitos en el Perú. Se decía que aquellas hermosas telas que llevaban en su interior, gustaba mucho a los pobladores de la ciudad vecina. Esta embarcación estaba dirigida por el capitán Vinicius, quien era un hombre muy bondadoso, de noble sentimientos y sobre todo, justo. Cuando el capitán se disponía a subir a su embarcación y próximo a partir, vislumbró cerca de él un hermoso huevo de color marfil, y pensó: "iDesde cuándo estará este huevo en la orilla del rio? ¿Parece ser un huevo de lagarto?"

Era raro para él, que entre la orilla del río hubiese un huevo rodeado de piedras. Pues los lagartos depositan sus huevos dentro de la vegetación para esconderlos de los depredadores. Continuó pensando que tal vez este haya sido arrasado por la corriente y llevado hasta allí. De cualquier manera no puedo dejarlo ahí, pensó. Agarró el huevo para llevarlo entre sus brazos. Subió a la embarcación y lo dejó dentro de una pequeña canasta.

El Reina María I, estaba listo para partir. Los pobladores se despedían emocionados de todos los pasajeros, ya que eran familiares de casi todo el pueblo. Y así fue. El barco zarpó lentamente con mucha tranquilidad, y los pasajeros muy felices.

Navegaron días y noches por las aguas del Amazonas. Aquel río que se mostraba sereno y tranquilo. Cruzaron todo el Brasil, hasta llegar a Leticia que es la frontera que separa a Colombia, Brasil y Perú. En aquel puerto bajaron todos los tripulantes y pasajeros, necesitaban cambiar sus reales por soles.

El capitán Vinicius hizo lo propio. Olvidando el huevo en el interior del barco. De pronto, el clima se puso feo, empezó a llover fuertemente, el cielo se llenó de 
nubes negras y empezó a caer truenos, rayos y relámpagos, uno de esos rayos impactó justo en medio de la embarcación. El capitán no podía creerlo. El Reina María I, se estaba quemando. Pero eso no era lo único que le preocupaba, pues recordó que el huevo que tanto había cuidado estaba vulnerable rodeado por esas llamas.

Trataron de sujetar el barco, pero no se pudo, la corriente lo llevó hacia la otra orilla, y allí terminó de quemarse. Vinicius, no pudo contenerse y rompió a llorar. Se sentía culpable de todo. Cayó de rodillas al piso arcilloso y golpeaba con sus fuertes manos morenas, su pecho.

De pronto, algunos tripulantes vieron a lo lejos una canasta que salía triunfante de aquel humo negro. El capitán levantó la mirada y vio aquella escena. ¿Era el huevo? Sí, lo era. Pidió una canoa para alcanzar a aquella canasta, pero, en el preciso momento en que se disponía subir a la embarcación artesanal, el río comenzó a incrementar su caudal y se puso turbulento. De todas maneras él quería ir a salvarlo, pero los pobladores no lo dejaron, pues era un riesgo para su vida.

Vinicius vio alejarse por el horizonte a aquella canasta cubierta por una tela de color verde y roja. Tristemente lloró, y mirando al cielo, pidió al Señor que proteja al único sobreviviente de la embarcación Reina María I.

El cielo amazónico relucía impecable, despejado y a lo lejos se distinguían los rayos del sol. Ainia parecía danzar en los aires, sus hermosas alas de color canela, jugueteaban con los rayitos de sol, que poco a poco empezaron a perderse en el azul del cielo. Ainia, cantaba y cantaba, dando los buenos días a todos los habitantes del bosque amazónico, su melodía aguda sonaba ham, ham, ham, ham, haaaaaaaaaa. Cuando se preparaba para aterrizar entre las hojas flotantes, se encendieron rápidamente sus ojos de color miel; vislumbró una canasta solitaria y dijo:

- ¿Qué hace esa canasta en medio del Amazonas? iTengo que investigarlo!

Se apresuró a descender. Aterrizó suavemente, para no llamar la atención, encima de la canasta. Asomó su cabecita ploma dentro y de pronto vio unos pequeños ojos rojos que se prendían presurosamente y se asustó. Retiró la cabeza inmediatamente, pero como era muy curiosa, pensó que de repente era producto de su imaginación, pues cómo podía haber unos ojos de color rojos. Nuevamente se asomó a la canasta, pero esta vez quitó con su pico ganchudo la tela que lo cubría, llevándolo por los aires hasta dejarlo encima de la copa de un árbol. Bajó inmediatamente y vio dentro de la canasta a un ser de color negro y pequeño, que estaba acostado encima de una camita blanca.

-¿Quién eres?-preguntó ella.

Pero él no respondió. Le increpó nuevamente:

-¿De dónde vienes? -y tampoco respondió. 
Entonces le preguntó:

- ¿Estás de vacaciones? ¿Pero dónde están tus padres?

No obtuvo ninguna respuesta. Dio varias vueltas alrededor de la canasta y vio una etiqueta que decía Pancho.

-iAh ya sé, te llamas Pancho! ¿Cómo no se me ocurrió antes? - dijo el ave.

El lagarto sonrió mostrando sus pequeños dientes, en un gesto de afirmación. Ainia, reflexionó por un momento, y susurró:

-Pobre Pancho, debe de estar solo. ¿Quién podría abandonarlo? Se ve tan vulnerable y muy hambriento. Qué puedo hacer yo, si soy solo un ave de paso.

Pancho miraba a aquella ave con dulzura e inocencia.

Ainia, tomó vuelo. Subió a la copa de un árbol y cogió una especie de fruta de apariencia morada, que por aquellos lugares le llaman caimito. Se lo entregó al pequeño Pancho e inmediatamente el caimito estaba en su estómago.

Ainia, jaló la canasta hasta la orilla del río. Recogió la tela roja y verde que había dejado encima de la copa del árbol. La amarró por el contorno del cuello de Pancho, simulando ser un pañuelo de marinero. Ainia, ayudó con mucho cuidado al pequeño a descender de la canasta al suelo y se posó encima de él, y juntos ingresaron al bosque.

Respiraron una y otra vez. Sintieron el aire puro y fresco que parecía venir desde aquellas grandes y verdes hojas frondosas. Para Pancho todo era nuevo, las hojas, las flores, los troncos, los frutos, no dejaba de sorprenderlo, Ainia muy contenta le explicaba todo lo que conocía, pues ella venía de un lugar muy lejano llamado Costa Rica. Y le dijo:

-Como te habrás dado cuenta, mi pequeño, soy un ave aventurera, mis abuelos eran mexicanos y mi madre nació en Venezuela, tengo muchos hermanos, primos y parientes que ni conozco, pero sé que existen; mi familia va desde el sur al norte de toda América, lo cual hace de este Continente, mi hogar; tienes que saber que sé hablar muchos idiomas, pues mi familia siempre me enseñó que para poder comunicarme con los demás es necesario hablar su idioma. Cuando emprendí mi gran viaje por las islas centroamericanas tuve que hablar inglés, francés, holandés y español. Ah!... pero también sé hablar portugués y un poco de italiano. Estuve aprendiendo a hablar quechua y algunas lenguas nativas del Amazonas. Me gusta mucho aprender nuevas culturas. Siento que es parte de mi historia. Pero bueno ya hablé mucho de mí. Dime pancho, itú sabes de dónde vienes?

Y Pancho le respondió:

-No. Yo no sé de dónde soy. Pero pienso que nací en el río, pues es ahí donde por primera vez te vi.

Entonces Ainia le preguntó: 
- ¿Y por qué nunca saliste de esa canasta rota?

Y él le respondió:

-Pues me daba miedo. Afuera se escuchaba muy feo. Pero ya no tengo miedo, porque tú estás conmigo y sé que nada me va a pasar.

Ainia le dijo:

-Es correcto, precioso, entonces tú eres peruano. Porque te encontré cerca de la Reserva Nacional de Marasha. Es un territorio hermoso y pertenece al Perú.

Pancho se quedó callado por unos momentos y de repente exclamó dijo:

-iSoy peruano!

Pancho había encontrado el lugar adonde pertenecía y se sentía muy feliz por eso.

Los dos siguieron caminando y conversando por varias horas hasta que vieron a unos seres trepados por los árboles que comían bananas. Y Pancho preguntó:

-¿Qué son esos seres?

Ainia le respondió:

- Mira Pancho, los de ahí se llaman monos Titi, son más delgados que los monos araña que están más arriba del árbol. Si alzas muchísimo más la mirada, podrás ver unos pájaros grandes de colores. iLo ves?

-Sí, los veo. ¿Y ellos cómo se llaman y por qué tienen la nariz tan grande? preguntó Pancho.

-Mira ellos se hacen llamar Tucanes y tienen el pico muy grande, porque eso les ayuda a controlar su temperatura corporal y también para pelar frutas -le dijo Ainia.

-Son muy hermosos - dijo Pancho-. Y rápidamente pensó en voz alta: Cuando sea grande, seré un Tucán para poder volar por los cielos.

Siguieron caminando y a lo lejos vieron unas nuevas aves, pero estas eran muy distintas. Pancho se sorprendió y dijo:

- ¿Por qué esos Tucanes no están volando y por qué tienen el pico tan corto?

-Esas aves no son Tucanes. Son Gallitos de las rocas. El color naranja y negro es muy característico en ellos. iHey! Vamos, Conozco a uno de ellos, te lo presentaré -le dijo Ainia.

- ¿Cómo están chicos?-dijo Ainia.

-iBien! iY ustedes?-dijeron las aves

-iPura vida! Les presento a Pancho. Él es peruano como ustedes -le explicó Ainia.

-Hola Pancho. Mucho gusto. Mira yo me llamo Florentino y él es Hilario.

-Mucho gusto señores. Yo soy Pancho y como ven soy un lagarto. 
-Cuéntame amigo. iHacia dónde van? -preguntó Florentino.

-iNo lo sé! -le dijo Pancho con voz dudosa.

Ainia interrumpió:

-Estoy mostrándole al muchacho nuestro hogar. Hemos caminado tanto. iQué ya estamos cerca de llegar a Leticia! Pues hablé con un delfín rosado, quien me dijo que probablemente allá pueda encontrar más lagartos y de repente reconozcan a Pancho.

En eso Florentino interrumpió:

-iAhhh!... Justo hoy se cumple un mes del naufragio de una embarcación y sería bueno que llevaran unas flores blancas como muestra de solidaridad. ¿Ainia, tú sabes qué ocurrió aquel día?

Y Ainia le respondió preocupada:

-No lo sé.

-Pues se dice que un barco venido del Brasil, trayendo telas, se quemó en medio del Amazonas y que afortunadamente no hubo ningún herido, pero ahí no queda todo, se cuenta que ese día ocurrió un milagro. El fuego empezó a incendiar todo. El capitán estaba desesperado por salvar una canasta que se encontraba dentro de la embarcación. Gritaba muy fuerte. Hasta lloró de la impotencia, pues no lograba sacar aquella canasta del fuego. Sin embargo, después de un largo rato salió flotando aquella misma canasta que el capitán quería con tantas fuerzas salvar. Pero como no pudo alcanzarlo, rogó al Señor de los Cielos para que lo cuidara. Y por cierto, estaba cubierta de una tela del mismo color del pañuelo que tiene este pequeño lagartito. iSe cuenta que en aquella canasta había un huevo, pero nunca se supo qué clase de huevo era! -sermoneó Florentino.

Ainia, estaba muy impresionada y casi sin habla, porque intuía, que aquel huevo era Pancho. Y pensaba qué podría hacer. Por eso, presurosamente se despidió de aquellas hermosas aves y emprendió la marcha hacia Leticia.

Caminaron por varias horas, hasta que llegaron a Leticia. Ainia invitó a Pancho a que jugara con algunas nutrias que estaban en aquel lugar. De repente apareció el oficial Capibara y Ainia le pregunta sobre aquel barco que se quemó en el río. Y el confirmó todo lo que le había contado Florentino, pero añadió algo más. Que el nombre de la embarcación siniestrada era Reina María I y que venía del Brasil, exactamente de Magazao.

Ainia no lo dudó y decidió partir hacia aquel lugar. Presentía que era su deber ir a buscar a la familia de aquel inofensivo lagarto.

Compró unos boletos de barco, con destino a Magazao. Llamó a Pancho y le dijo:

-Amigo qué te parece si ahora vamos a visitar a unos parientes que tengo en el Brasil. 
Pancho se emocionó de poder conocer a más amigos. Subieron rápidamente al barco que estaba por partir. Pancho miró por el cobertor y se despidió de las nutrias. Él estaba muy feliz, era su primera vez en un barco. Se dispuso a comer un caimito. Era una de sus frutas favoritas,

De pronto sintió que alguien lo miraba y decidió saludarlo. Pero aquel pequeño pasajero se alejó de él para llamar rápidamente a su mamá, y dijo:

-iMamá! iMamá este lagarto feo y negro me quiere comer!

Aquella mamá miró a Pancho y le dijo a su hijo:

-iNicolás! No digas eso, que él es un niño igual que tú.

La señora Hormiguero se acercó a Pancho y le dijo:

-¿Pequeño, dónde está tu madre?

Pancho alzó la mirada y triste le respondió:

-Yo no conocí a mi mamá. Pero Ainia es como mi madre. Ella es muy buena y me cuida de todos los que quieren hacerme daño.

-iAh! entiendo - dijo la señora Hormiguero. Te pido disculpas por el comportamiento de mi hijo, Nicolás. iHlijo ven! Ofrécele unas disculpas a Pancho.

Y el niño le expresó su disculpa por haberlo ofendido.

La señora Hormiguero dijo con firmeza y sabiduría:

-Nunca debemos juzgar a nadie por su apariencia, lo mejor de las personas no se ve...

Y así pasaron los días. Hasta que llegaron al puerto de Magazao. Descendieron del barco y caminaron hacia donde había una señal de información turística, preguntaron si había alguna embarcación llamada Reina Isabel I. En ese momento apareció por debajo de unos libros el señor serpiente, quien era el guía turístico y con voz ronca les dijo que esa embarcación nunca fue habilitada después del accidente.

Ainia preguntó por el capitán. La serpiente pensativa les respondió:

-Se dice que el capitán de aquella embarcación viajó muy lejos, hacia el horizonte verde. No se sabe a dónde exactamente. Pero lo que se conoce es que él salvó a un huevo de lagarto que encontró cerca de su barco, antes de partir de este puerto con dirección al puerto de lquitos, y por esa acción es considerado el protector de la selva amazónica sudamericana.

Ainia entendió todo. Pancho era hijo de aquel honorable capitán. Y sabía que en algún lado del mundo su padre lo estaría buscando. Ella se comprometió a seguir cuidándolo hasta que pudiera emprender su propia búsqueda y descubrir quién era.

- ¿A dónde vamos? - preguntó Pancho a Ainia.

Y ella le respondió como susurrándole:

-A casa, mi pequeño, a casa. 